\title{
Interactive comment on "Study On The Driving Mechanism Of Hydrologic Drought In Karst Basin Based On Landform Index: A Case Study of Guizhou, China” by Zhonghua He et al.
}

\section{Anonymous Referee \#1}

Received and published: 1 June 2018

This paper is focused on spatial and temporal variations of hydrological droughts using a standardized runoff index and geomorphologic indices for the karst drainage basin of Guizhou, China. The paper is a new research study and is generally well-written as it explains the methodology, the mathematical framework and the assumptions used. However, the application research part needs improvements and corrections to verify the novelties of the method employed in the study area. Based on this general comment the following points should be addressed and clarified.

1. Threshold Selection. Please provide information on threshold selection. Why the authors select a fixed threshold (Mean Monthly Flow, MMF if I understood correctly).

Printer-friendly version

Discussion paper 
Why a variable threshold method is not selected for this study (e.g. Van Loon, 2015)? I would expect from the authors to use a monthly varying threshold for this type of presented analysis. Please justify this issue on the revised manuscript.

2. Regional Analysis (Page 5 and 6 of the manuscript). Please explain how the regional analysis is performed? The authors use the MMMF index? "And taking the MMMF of sampling sites as $Y$ axis and the series of sampling sites as $X$ axis". Is MMMF a regional index and how is derived? Is it the mean? Do you think that the mean index is representative considering the small dataset of 10 years? I would suggest to use an unbiased index if of course is it possible (maybe the median of the sites?). Please address this issue on the revised manuscript.

3. Standardization procedure of runoff index. (Equation 2 application). Please explain in detail the standardization procedure of the DI (the relative water deficit). Equation 2 is valid only when the variables are close to nornal distribution. This should be addressed in the revised manuscript. For example several theoretical distributions could be tested on DI values or if the data do not follow nornal distribution normalization techniques could be followed (i.e. Box-Cox transformation in Vasiliades et al., 2011). Furthermore, please take into account in your analysis the small temporal dataset in your analysis. Usually $>30$ years are needed to derive drought indices. Therefore, I am quite skeptical with the use of the term with the mean in Equation 2. I would recommend to the authors to use a non-parametric approach in their study due to small dataset in the derivation of the standardized index or to use a Box-Cox transformation to resemble the normal distribution. Please address this issue in the revised manuscript.

4. Correlation analysis between standardized runoff index and geomorphologic indices. Please provide evidence that the employed indices follow the normal distribution. This must be demonstrated in the revised manuscript (a correlation matrix could be useful on this). If this is not the case different evaluation techniques could be followed (e.g. nonlinear techniques based on the mutual information and/or partial mutual information , non-parametric statistical tests (Kendall's tau and Spearman's rho rank

Printer-friendly version Discussion paper 
correlation coefficients could be used as alternatives of the Pearson coefficient).

5. since several frameworks have been developed to account nonstationarity (like the Generalized Additive Models for Location, Scale and Shape parameters, GAMLSS) could be included in the revised manuscript for comparison purposes. I would suggest to the authors to use their models with linear, quadratic and cubic terms in time to demonstrate that the employed models are appropriate and could be used subsequently in the simulation experiments.

Minor Comments

6. Line 95 - Previous works of the authors. The authors should explain in detail the novelty of this study in comparison with the previous works of the authors. A paragraph explaining the differences from these previous works should be included in the manuscript.

7. Lines 97-98. Correct the reference in the manuscript "Feng, 1997 \& 1997".

8. Line 169. Correct the reference "Feng et al., 1997" in the text or in the bibliography list. There is not Feng et al., 1997 in the reference list.

\section{References:}

Van Loon, A. F. (2015), Hydrological drought explained. WIREs Water, 2: 359-392. doi:10.1002/wat2.1085.

Vasiliades, L., Loukas, A. \& Liberis, N. (2011), A water balance derived drought index for Pinios river basin, Greece. Water Resour Manage 25: 1087-1101. https://doi.org/10.1007/s11269-010-9665-1.

For the motivations listed above, the paper in its present form needs revisions in order to evaluate the innovative character of the proposed method. The paper is of general interest for international audience and merits publication in NHESS journal when the major revisions and comments are addressed. Addressing these comments will

Printer-friendly version

Discussion paper
Interactive

comment 
improve the quality of the paper and help the general reader of the paper.

Interactive comment on Nat. Hazards Earth Syst. Sci. Discuss., https://doi.org/10.5194/nhess2018-10, 2018.
NHESSD

Interactive

comment 